\title{
Challenging Deficit Dispositions: A Canadian Equity-Based Teacher Education Initiative
}

\author{
Manu Sharma \\ University of Windsor
}

\begin{abstract}
As educators, we often struggle with recognizing our personal biases but rarely do we critically examine institutions and programs that are known to be educational ones, about the biases inherent in them. Interestingly, deficit dispositions sometimes (un) consciously underlie and sometimes even reinforce the foundations of programs, initiatives, and institutions that are suppose to challenge and minimize inequities in education. This article will examine and explore a wellintentioned collaborative equity-based teacher education initiative used in a Canadian university in its Bachelor of Education program. This initiative used culturally relevant and responsive pedagogy as its theoretical framework. In particular, an analysis of three rich data segments, which emerged from the semistructured interviews conducted with teacher candidates and associate teachers, will be examined. The findings demonstrate that we have begun to make some progress in developing and trying out equity-based initiatives in teacher education programs, however it is important to be critical of university cultures that these programs run in.
\end{abstract}

\section{Introduction and Context}

This article emerges from a larger critical practitioner research study that examined an eight month long initial teacher education initiative named the Diverse Schools Initiative (DSI) developed by the Centre for Equity (CE) in a Canadian University, which emphasized an equity approach towards education known as, culturally relevant and responsive pedagogy (CRRP). CRRP was sought out by the developers of the DSI who believed that both culturally relevant pedagogy and culturally responsive teaching aimed at the same goal of making public schooling more equitable. The unique aspect of the initiative was that the developers of the DSI also instructed the classes to teacher candidates in the Bachelor of Education programme and a small group of ten associate teachers who agreed to be participate in the DSI. Only eight of the associate teachers and ten of the teacher candidates participated in the semi-structured interviews for this larger study.

According to the developers of the DSI, the aim of this initiative was to create an equity- based conversation amongst teacher candidates and their associate teachers. The developers of the DSI piloted using ten teacher candidates and their respective associate teachers; each of the participants were randomly chosen. The participants attended seminars and classes on culturally relevant and responsive pedagogy (CRRP) given by the developers of the DSI at the university. In this particular article, we investigate how shared knowledge of CRRP informs and influences the practicum experience for both teacher candidates and their associate teachers with respect to their understanding of deficit thinking and practices in a classroom setting. We examine three excerpts from the larger interview data collected. The research question that was asked to teacher candidates and associate teachers, in particular to the three excerpts was: How (if at all) does the DSI address the deeper roots of deficit thinking in inner city schools (with respect to teaching practices and pedagogical approaches)? The three excerpts stood out as they shared a deep-seated unconscious deficit perspective that was based in the school culture/institution in which teacher candidates and associate teachers worked in and as a result personally inherited it.

\section{Theoretical Framework}

Educators have struggled to build bridges across the contrasting experiences of diverse inner city students and their teachers by introducing various discourses, pedagogies and teaching frameworks. These have been based predominantly on discourses of anti-racism education, multicultural and inclusive education, culturally relevant pedagogy, and cultural responsive teaching frameworks. As all of these pedagogies share a common goal of closing the gap between teachers and their students to create an equitable and high quality educational experiences, there is a tremendous amount of overlap among them. This article will focus on 
culturally relevant pedagogy and cultural responsive teaching.

Gloria Ladson-Billings [1][2][3] and Geneva Gay [4] are understood to be the first scholars to coin the terms "culturally relevant pedagogy" [2][3] and "culturally responsive teaching” [4] ${ }^{1}$. Ladson-Billings [2] presented the term "culturally relevant pedagogy" which she defined as a pedagogy that "not only addresses student achievement but also helps students to accept and affirm their cultural identity while developing critical perspectives that challenge inequities that schools (and other institutions) perpetuate” (p. 469). Moreover, Ladson-Billings [1][2][3] encourages teachers to recognize the internalization of deficit thinking that is prominent in the lives of many marginalized students.

There are many negative experiences that racially marginalized students encounter at school in different ways, such as being ostracized by their own peer community when they excel at school. Deficit attitudes, actions and beliefs ${ }^{2}$ are often based on the internalized deficit thinking marginalized students have accepted as their norm. In other words, they believe that as a racially marginalized student they cannot be intelligent, thus they consider their peers who excel academically as "acting White" [2][3]. As a result, most racially marginalized students who excel academically are isolated and often abandon their cultural roots [2][3].

In addition, to use culturally relevant pedagogy, three themes need to be addressed by the teacher. First their conceptions of self and others which recognize the power and privilege different identity markers create in a classroom environment. Second, their social relations with students and the power that is invested in them and the interactions they have with students. Finally, how they understand knowledge beyond the confines of curriculum and how they communicate this with children [2][3]. All three themes should be assessed in a multifaceted and flexible way. Once the teacher addresses these three themes and follows through on the three goals of culturally relevant pedagogy for students, there becomes a "critical hope" ${ }^{3}$ for addressing the inequities in schools and the gap between teachers and racially marginalized students.

Gay's [4] term culturally responsive teaching was also designed to address a challenge that many teachers

\footnotetext{
${ }^{1}$ The developers of the DSI throughout their interviews agreed upon this understanding of Ladson-Billings and Gay as being the key scholars who originated culturally relevant pedagogy and culturally responsive teaching.

${ }^{2}$ My understanding is that deficit attitudes, actions and beliefs are cyclical and are derived from three major frameworks; pseudoscientific, sociological-cultural, and socio-economic as described in my Master's thesis [12].

${ }^{3}$ Critical hope is a term that Ladson-Billings refers to in her talk on youtube, for more information here is the link www.youtube.com/watch?v=251Uc05SjqE
}

were facing during the twentieth century, when demographics were changing rapidly and the achievement gap between racialized and non-racialized students was increasing. According to Gay [4] learning how to teach diverse students was a real challenge and required a shift in the way teachers taught and what they taught. Gay claimed that in order to teach to diverse students, teachers would need to use students' personal frames of reference as the starting point of meaningful and deep education. Gay believed if the education was personalized to each student they would be engaged in learning and thus, would improve academically. Before going into detail on Gay's conception of culturally responsive teaching, I wonder what she would explain to be the role and influence of teacher identity and how this teacher identity complicates, interrupts, alters, and influences how the teacher understands students' personal frames of reference. In Gay's account, it seems as though the teacher becomes a separate identity from their teaching pedagogy; how can a teacher's own personal frames of reference not be looked at when trying to understand their students' personal frames of reference?

Gay [4] explains culturally responsive teaching as having five essential components. These are:

(1) developing a knowledge base about cultural diversity;

(2) including ethnic and cultural diversity content in the curriculum;

(3) demonstrating caring and building learning communities;

(4) communicating effectively with ethnically diverse students; and

(5) responding to ethnic diversity in the delivery of instruction (p. 106).

Gay [4] describes explicit knowledge about cultural diversity as knowing the cultural characteristics and contributions that particular ethnic groups have made. She contends that teachers should have detailed factual knowledge about the particularities of ethnic groups, such as achievements and contributions that each ethic group has made to different disciplines. After gaining this explicit knowledge of the cultures present in their classroom, teachers have a responsibility to visually display this knowledge, which is the second component of culturally responsive teaching (p. 108).

Gay [4] contends that is absolutely necessary if educators are to reach these diverse students; "[t]he answer is not denial or evasion but direct confrontation and thorough, critical knowledge of the interactive relationships between culture, ethnicity, communication, and learning and between individuals and groups” (p. 111) 
In addition, several secondary literature pieces on culturally relevant pedagogy and culturally responsive teaching are presented in this review. Most of the secondary literature draws upon Gay's work on culturally responsive teaching and Ladson-Billings' work on culturally relevant pedagogy. While reading and reflecting upon these scholarly articles, I observed that the terms culturally responsive and culturally relevant pedagogy were used interchangeably by many of the authors. Indeed, very often when scholars argued a perspective on making teaching more relevant to the students' lives they would quote both Ladson-Billings and Gay to support their claims. Thus, for many scholars it seems that both culturally responsive teaching and culturally relevant pedagogy have the same prospective goals, audiences, and as a result can be used interchangeably and in union.

The literature on culturally relevant pedagogy [1] and culturally responsive teaching [4] are used to help gain an insight on the theoretical basis of CRRP as that is what informed the DSI. However, to be critical of this theoretical framework I also used an anti-neoliberal lens informed by the work of Apple [5], McLaren, Macrine, and Hill [6], Hyslop-Margison and Sears [7] and Giroux H. and Giroux S. [8] for the theoretical framework of this article.

\section{Methodology and Methods}

This is a article is informed by a practitioner research methodology described by Cochran-Smith and Lytle [9]. As Campano and Simon [10] state there are multiple versions of practitioner research; in this article, a critical version of practitioner research that is also action based is used.

The main reason practitioner research methodology is used in this study is because, I explore an initiative put forth by an initial teacher education program that involves educators in the context of public school practicums. According to Marilyn Cochran-Smith and Susan Lytle [9], the two core concepts of practitioner research are:

(1) teaching is a deliberative (not a technical) profession, practitioners generate knowledge for practice, and (2) contextualized questions and uncertainties are brought forward by practitioners which are based on issues of teaching and learning at all levels (p. 20).

This study questions key practices in teacher education; in particular, practices of teachers, associate teachers, theory and practice, equity-based pedagogy, and critical pedagogy. Moreover, this study has been undertaken in an attempt to generate new knowledge for practice that teacher education practitioners can use. The questions that emerge from the content and analysis of the interviews I conducted present several uncertainties and questions for teacher candidates and associate teachers. Furthermore, it is important to note that these questions and uncertainties came from practitioners [9] “...examining their own assumptions, deepening their local knowledge by gathering data, asking questions, and working towards social justice" (p. 74).

\section{Methods and Analysis}

In the larger study on which this article is founded upon, collaboration was undertaken through the process of "member checking" 4 with the developers of the DSI. I used the strategy of "member checking" to ensure that my interpretations of their responses in interviews were accurate, and also to provide them an opportunity to provide their feedback on initial themes and findings that emerged during the data analysis phase of this study. The assumptions about links of knowledge, knowers, and knowing were also articulated by the participants in this study during their interview process and highlighted through the study's findings.

Moreover, these assumptions were significant because they provided insight on the nuances between various participants' interpretations of the content in the DSI, recognizing whose interpretations count, and how this affected the experience each participant had in the DSI. The professional context of this larger practitioner study was the university and school site-based classrooms in which field-notes were taken. In addition, the reflections, statements, questions, and messiness involved in understanding participants' voices in class observation in contrast to in interviews demonstrated to me the blurred boundaries of inquiry and practice. Thus, there were multiple opportunities of data gathering (field notes, interviews, critical reflections) and analyzing the data was complex and often multi-layered when exploring what patterns/themes appeared in the data.

\section{The Three Excerpts and Findings}

In relation to the DSI itself, many participants in the interviews articulated several concerns about the DSI and how sometimes there was a disconnect between how CRRP work was understood and taken up in the Initial Teacher Education program. Interestingly, how CRRP was understood and taken up in the participant's teaching experiences during practicum was inconsistent with what the developers of the DSI had taught. In particular, the practices and pedagogy of CRRP as understood by the participants in the following three

\footnotetext{
4 "Member checking" is a phrase coined by Patti Lather [13] that contributes to a catalytic validity.
} 
excerpts demonstrate a lack of addressing deficit thinking assumptions and practices. Instead, the excerpts provide insights on why they were not addressing deficit thinking in their classrooms. It is important to note, that the following excerpts were collected in response to "How does the DSI address the deeper roots of deficit thinking in inner city schools?”

\section{Excerpt One:}

"One of our students here, actually two of them were shot at over their fence because people thought they were a snitch...a student's sister was shot in the head...that type of gang culture dominates their world not networking, ipads, technology....if they have phones they are texting one another locally because they can't get out locally, many of them are not allowed out. All of this out of fear, the parents are working hard, and the kids are locked up at home with elder siblings and then they text their parents to let them know that they are home. To ignore those pressures in their lives.... and something that needs to be acknowledged." (Stella, interview, 2010, p. 5)

In this excerpt the associate teacher recognizes that lives of inner city students are different- however, this is all that is emphasized. Instead of looking at the challenges and obstacles that these communities face and overcome successfully or the rich sense of culture and assets they have, a focus is made on the violence. I wonder, if this adds to stereotyping? What can be done with such a narrative in relation to creating equity based initiatives in teacher education? How and why should we prepare our teachers to enter into honest and courageous dialogue about this?

\section{Excerpt Two:}

"I want to clarify first of all that I don't feel that way. But in my years of teaching, I hear that from them, not all of them but some of them come into school saying that they can't learn anything because (left blank)...but umm...but because there is a common stereotype about where they live...sometimes I leave these remarks and sometimes I address them and question it with them... when they are doing things that are about the world in the classroom making their background relevant, for instance we are doing a unit on rivers and one of them has seen the Nile river and so I want them to wow us...there is a richness there and just because you live in the community housing that doesn't mean you have no richness. So I always challenge this when I hear this...” (Janene, interview, 2010, p.4)

The associate teacher in this excerpt highlights the experience of the inner city student who has seen the Nile river as a "wow" factor. I wonder would it be a "wow" factor if a middle class or upper class student saw the Nile River on their vacation? Does the associate teacher have a preconceived notion of what is "normal" for inner city students to have experienced? Is the good intention of highlighting the Nile as a "wow" factor a way to close the gap?

Excerpt Three:

"Sometimes I think this idea is in our students' minds because they know that people are treated differently even though at school teachers often say that we are all the same and we need to treat each other equally. Students know that life doesn't make them equally. I felt as though if I did not empower them to talk about race in the ads they might have the urge to assume everything is equal.” (Lilly, interview, 2010, p. 8)

In this third excerpt, the teacher candidate contradicts herself by claiming that teachers teach that students are equal and then in her act of "empowering" the students she demonstrates that there is power difference between her (a Caucasian teacher) and the students (racially marginalized students). Why and how do power dynamics at play when educating inner city students reinforce and perpetuate the status quo? How can educators interrupt this air-tight cycle?

Beyond the immediate critical questions that come to mind (as stated after the excerpts), let's examine the larger conclusions. Firstly, all three educators believed that there was no deficit thinking present in the school or classroom because they did not have that bias toward racially marginalized students. Secondly, the second educator believed by spotlighting inner city students that it was balancing out the playing field. Lastly, the third educator seemed to repeat and reinforce the power imbalance between racial and hierarchical spaces despite wanting to decrease it.

It is interesting to note that all three of responses provide a detour from what lies beneath, that is, the roots of deficit thinking. This appears to be ironic since this well-intentioned equity initiative is falling short of acknowledging and addressing the roots of deficit thinking, when the purpose was to use CRRP to create equitable classroom practices and pedagogical approaches.

\section{Discussion and Conclusion}

Allowing practitioner research to be practiced in initial teacher education programs through processes of inquiry, reflection, and questioning creates issues and tensions that are at once productive and disruptive at the university; which, in turn, are essential to interrupt the traditional hierarchy of knowledge. I believe that these disruptive moments create productive tensions and discomfort, which help to catalyze change in traditional 
university structures and school cultures. Some of the questions that these excerpts give birth to on the level of teacher education programs are:

1.How might we address our (un)conscious biases when working with inner city students?

2.How might we challenge and redirect our participation in such well-intentioned equity initiatives, enabling us to make a meaningful contribution towards creating critical and robustly democratic public schooling experiences?

3.What would an authentic equity initiative in teacher education look like, if its goal was to transform public schooling experiences for racialized and marginalized students?

While, I understand that asking these difficult and complex questions can be overwhelming, it is important to ask them as it is only from dissonance and often discomfort do we grow. In the words of Cochran-Smith and Lytle [9], "[a]t times, [such research] can make working within the university context difficult; however, it can also be generative-suggesting new questions and prompting further critique about schooluniversity relationships" (p. 97). It is with this understanding of practitioner research bringing about generative questions when being carried out in a university setting and using the insights of the participants of this study, that I share these findings in this article. Thus, I believe the difficulties that arose out of conducting this critical practitioner research study at the university were well worth the effort, as the generative knowledge and questions that resulted due to dissonance at times, such as in this instant, is truly insightful! It is with the hope such questions and thoughts that I urge educators to envision bold and courageous equity-based teacher education initiatives.

\section{Authors note}

This paper proposal draws heavily upon my doctoral dissertation [11], which was approved by the University of Toronto's ethical review board.

\section{References}

[1] Ladson-Billings, G. (1994). The Dreamkeepers: Successful Teachers for African-American Children. San Francisco: Jossey-Bass.

[2] Ladson-Billings, G. (1995). Toward a Theory of Culturally Relevant Pedagogy. American Educational Research Journal, 32(3):465-491.

[3] Ladson-Billings, G. (1995). But that's Just Good Teaching! The Case for Culturally Relevant Pedagogy. Theory into Practice, 34(3):159-165.
[4] Gay, G. (2002) Preparing for Culturally Responsive Teaching. Journal of Teacher Education, 53(2):106116.

[5] Apple, M. (2006) Educating the "Right" Way: Markets, Standards, God, and Inequality. New York: Routledge.

[6] Macrine, S., McLaren P. \& Hill D. (Eds.) (2010). Revolutionising pedagogy: Education for social justice within and beyond global neo-liberalism. New York: Palgrave Macmillan

[7] Hyslop-Margison, E. J., \& Sears, A. M. (2006). Neoliberalism, globalization and human capital learning. Dordrecht, NL: Springer.

[8] Giroux, H. A., \& Giroux, S. S. (2006). Challenging neoliberalism's new world order: The promise of critical pedagogy. Cultural Studies $\leftrightarrow$ Critical Methodologies, 6(1), 21-32.

[9] Cochran-Smith, M. and Lytle, S. (2009) Inquiry as Stance: Practitioner Research for the Next Generation. New York: Teachers College Press.

[10] Campano, G., and Simon, R. (2010). Practitioner research as resistance to the normal curve. In $\mathrm{C}$. Dudley-Marling \& A. Gurn (Eds.), The myth of the normal curve, 221-240. New York: Peter Lang.

[11] Sharma, M. (2013). Exploring culturally responsive and relevant pedagogy in initial teacher education: A critical practitioner research study. Toronto: University of Toronto Press.

[12] Sharma, M. (2009). Inner city students: stamped, labeled and shipped out! Deficit thinking and democracy in an age of neoliberalism. Toronto: University of Toronto Press.

[13] Lather, P. (1986) Issues of Validity in Openly Ideological Research: Between a Rock and a Soft Place. Interchange, 17(4): 63-84. 